\title{
Contribuições da Linguística Cognitiva para o estudo de línguas de sinais
}

\author{
Contributions of Cognitive Linguistics to the Sign Language study
}

\section{Valeria Fernandes Nunes}

Universidade Federal do Rio de Janeiro - UFRJ - Brasil

\begin{abstract}
Resumo: Por meio de uma pesquisa bibliográfica e qualitativa, foram analisados dois sinais - APRENDER/ESQUECER - em sete línguas de sinais (Língua Brasileira de Sinais, Língua de Sinais Francesa, Língua de Sinais Americana, Língua Gestual Portuguesa, Língua de Sinais Sueca, Língua de Sinais Chinesa e Língua de Sinais Japonesa), totalizando um estudo de catorze sinais. Os sinais foram extraídos do instrumento linguístico internacional "Spread the Sign Web Dictionary - SWD", produto do Centro Europeu de Língua de Sinais, em Örebro, na Suécia, desenvolvido pela Universidade de Örebro. Para a análise, também realizamos entrevista com o professor sueco Thomas Lydell-Olsen, coordenador do SWD. O problema principal é compreender se sinais em línguas de sinais apresentam relações icônicas motivadas por processos linguístico-cognitivos. Para isso, analisam-se como sinais podem estar atrelados à corporificação, à metáfora, à metonímia e aos esquemas imagéticos. Resultados preliminares apontam que a relação com o corpo (corporificação) tem sido mantida favorecendo a iconicidade cognitiva. Dessa forma, o desenvolvimento deste estudo proporciona um saber metalinguístico, promovendo análise linguística e valorização das línguas de sinais.
\end{abstract}

Palavras-chave: língua de sinais; linguística cognitiva; iconicidade.

Abstract: Through a bibliographical and qualitative research, two signs - LEARN / FORGET - were analyzed in seven sign languages (Brazilian Sign Language, French Sign Language, American Sign Language, Portuguese Sign Language, Swedish Sign Language, Chinese Sign Language and Japanese Sign Language), totaling a study of fourteen signs. The signs were extracted from the international language instrument "Spread the Sign Web Dictionary - SWD", product of the European Center for Sign Language, in Örebro, Sweden, developed by the University of Örebro. For the analysis, we also conducted an interview with Swedish professor Thomas Lydell-Olsen, SWD coordinator. The main problem is to understand whether sign languages present iconic relations motivated by linguistic-cognitive processes. For this, we analyze how signs can be linked to the embodiment, the metaphor, the metonymy and the image schemes. Preliminary results point out that the relationship with the body (embodiment) has been maintained favoring cognitive iconicity. Thus, the development of this study provides a metalinguistic knowledge, promoting a way of describing and valuing sign languages.

Keywords: sign language; cognitive linguistics; iconicity. 


\section{Introdução}

As línguas de sinais não são universais, porque cada país, com suas características históricas e culturais, forma seus sinais e suas respectivas gramáticas. Entretanto, apesar de não ser universal, essa comunicação visual pode estar relacionada a questões corporais essenciais, ligadas ao homem, à mente e a como é estruturado biologicamente o corpo humano.

Pensando nessas ações relacionadas ao corpo, busca-se analisar como diferentes línguas de sinais podem estabelecer relações corporificadas e icônicas de acordo com a maneira em que a realidade é retratada em determinada cultura. Em outras palavras, a percepção visual é expressa no polo fonológico em línguas visuoespaciais através de fenômenos linguístico-cognitivos (corporficação, metáforas, metonímias, esquemas imagéticos e iconicidade cognitiva).

Por meio de uma pesquisa bibliográfica e qualitativa, foram selecionados dois sinais (APRENDER/ESQUECER) das seguintes línguas de sinais modernas: Língua Brasileira de Sinais (LSB - Libras), Língua de Sinais Francesa (LSF), Língua de Sinais Americana (ASL), Língua Gestual Portuguesa (LGP), Língua de Sinais Sueca (LSS), Língua de Sinais Chinesa (LSC) e Língua de Sinais Japonesa (LSJ).

A pesquisa contou com a colaboração da ferramenta internacional de divulgação e estudo de línguas sinais Spread the Sign Web Dictionary - SWD (www.spreadthesign.com ) e com entrevista com 0 coordenador dessa base de dados, o professor sueco Thomas Lydell-Olsen.

Criado em 2006, o site SWD é produto do Centro Europeu de Língua de Sinais, em Örebro, na Suécia. O dicionário tem sido desenvolvido pela Universidade de Örebro, com a parceria inicial de instituições sobre surdez da República Checa, da Espanha, da Lituânia, de Portugal e do Reino Unido. Em 2010, registra-se a participação no projeto da Alemanha, da Turquia e da França. Em 2015, o dicionário já contava com a participação de vinte e cinco países.
Dessa forma, este estudo visa ao estudo comparativo de línguas de sinais a fim de verificar como a iconicidade cognitiva ocorre por meio de processos linguístico-cognitivos, que podem estar atrelados à corporificação, a metafóras, a metonímias e aos esquemas imagéticos, fatores colaboradores da Iconicidade Cognitiva.

\section{Escolhas metodológicas}

Nesta pesquisa bibliográfica e qualitativa, este estudo investigou dois sinais (APRENDER/ESQUECER) em sete línguas de sinais, totalizando uma análise de catorze sinais. Essas línguas de sinais foram selecionadas, porque este estudo visa compreender o processo da iconicidade cognitiva em línguas com origens diferentes. As Línguas de Sinais Americana e Brasileira tiveram influências da Língua de Sinais Francesa; a Língua Gestual Portuguesa teve influência da Língua de Sinais Sueca; e as Línguas de Sinais Chinesa e Japonesa não receberam influências nem da Língua de Sinais Francesa e nem da Língua de Sinais Sueca. Essas línguas (Chinesa e Japonesa) revelam aspectos culturais diferentes dos do ocidente, local em que se desenvolve a pesquisa. Assim, foram selecionados cinco países do ocidente e dois do oriente.

Os sinais desta pesquisa foram extraídos do site Spread the Sign Web Dictionary - SWD, que apresenta vídeos de sinais de várias línguas de sinais. A produção de vídeos possibilita a visualização dos sinais, destacando as expressões faciais. Vale ressaltar, contudo, que há alguns sinais não disponibilizados pelo dicionário para todas as línguas de sinais em estudo.

O site disponibiliza vídeo com a reprodução do sinal, áudio e escrita da palavra usada na língua oficial de cada país, possibilidade de consulta em outras línguas de sinais por meio da seleção da bandeira de cada país e, em alguns casos, breve definição escrita do significado do sinal selecionado.

Conforme entrevista por e-mail com 0 pesquisador Thomas Lydell-Olsen, em vinte e um de dezembro de dois mil e dezessete, há registro de 
trinta e uma línguas de sinais, a saber: Búlgaro, Inglês (Estados Unidos), Inglês (Reino Unido), Estoniano, Finlandês, Francês, Grego, Sinais Internacionais, Islandês, Italiano, Japonês, Croata, Letão, Lituano, Polonês, Português (Brasil), Português (Portugal), Romeno, Russo, Espanhol (México), Espanhol (Espanha), Sueco, Checo, Turco, Alemão (Áustria), Alemão (Alemanha), Ucraniano, Bielorrusso, Urdu (Paquistão), Grego (Chipre) e Espanhol (Cuba). De acordo com a mesma entrevista, há equipe especializada, com participação de surdos e de linguistas que analisam os sinais que serão inseridos no dicionário.

$\mathrm{Na}$ entrevista com Thomas Lydell-Olsen (2017), foi descrito que os colaboradores foram selecionados a partir do interesse deles em contribuir com o dicionário. Assim, foi citada a participação dos seguintes pesquisadores: no Brasil, Dra. Lodenir Becker Karnopp (Professora Associada do Departamento de Estudos Especializados e do Programa de Pós-Graduação em Educação, na Universidade Federal do Rio Grande do Sul UFRGS); em Portugal, Universidade do Porto, no Japão, Universidade de Tsukuba; na China, Dr Junhui Yang (Professor sênior em BSL e Estudos Surdos Escola de Ciências Sociais e Humanas, Universidade Central de Lancashire - UCLan); na Suécia, Universidade de Örebro. Não foram mencionados na entrevista os_pesquisadores dos Estados Unidos da América e da França.

Tendo em vista que esta pesquisa é desenvolvida no Brasil e há diversas fontes de consulta para os sinais da Libras, que não estão disponíveis no Spread the Sign Web Dictionary $S W D$, foram consultados sinais com a variação do Rio de Janeiro, estado do Brasil em que se desenvolve esse estudo, no Dicionário Enciclopédico Ilustrado Trilíngue da Língua de Sinais Brasileira Novo Deit-Libras (CAPOVILLA et al, 2015).

O Novo Deit-Libras (2015) é fruto de um amplo programa de pesquisas, por duas décadas, empreendido pelo professor e pesquisador Fernando César Capovilla, na Universidade de São Paulo, com financiamento das seguintes agências de fomento à pesquisa: Conselho Nacional de Desenvolvimento Científico e Tecnológico (CNPq), Coordenação Nacional de Aperfeiçoamento de Pessoal de Ensino Superior (Capes) e Instituto Nacional de Estudos e Pesquisas Educacionais Anísio Teixeira (Inep).

O dicionário é composto por 10.296 sinais, com 9.021 verbetes em Português que correspondem aos 10.296 sinais da Libras. Os verbetes em Inglês contabilizam um total de 13.757. Para a elaboração do dicionário, em relação à bibliografia, foram consultadas cerca de 2.000 referências. O escopo da validade dos sinais ou da entrada de sinais no corpus do Novo Deit-Libras (2015) abrange onze estados brasileiros (São Paulo, Rio de Janeiro, Minas Gerais, Mato Grosso do Sul, Bahia, Ceará, Pará, Santa Catarina, Paraná, Paraíba e Rio Grande do Sul) e o Distrito Federal.

\section{Parâmetros fonológicos}

Nesta seção, são descritos parâmetros fonológicos da Língua Brasileira de Sinais - Libras a fim de exemplificar algumas especificidades linguísticas presentes nos estudos de línguas de sinais que diferem na produção de línguas orais.

Em relação a uma perspectiva fonológica, segundo Quadros e Karnopp (2004), as propriedades de cada parâmetro são as seguintes: (i) Configuração de mão (CM); (ii) Locação da mão ou Ponto de articulação (L); (iii) Movimento da mão (M); (iv) Orientação da mão (Or); (v) Expressões não manuais (ENM) ou Marcas Não Manuais (MNM).

A Configuração da(s) mão(s) são formas das mãos, podendo ser o uso do alfabeto manual ou de outras formas realizadas pelas mãos (BRITO, 2010 [1995]). Essas formas podem ser produzidas pela mão direita para os destros, esquerda para os canhotos ou por ambas, quando o sinal exigir o uso das duas mãos.

O Ponto de articulação (PA) ou Locação da mão (L) é o espaço dentro de um raio de alcance onde a mão configurada predomina, ou seja, local de produção do sinal, podendo tocar alguma parte do corpo ou estar em um espaço neutro, que é um 
espaço fora das principais áreas de articulação cabeça, tronco, braço e mãos.

Em relação ao Movimento, alguns sinais podem ter ou não movimento. Para Brito 2010 [1995], o Movimento é um

parâmetro complexo que pode envolver uma vasta rede de formas e direções, desde os movimentos internos da mão, os movimentos do pulso, os movimentos direcionais no espaço até conjuntos de movimentos no mesmo sinal. (...) $\mathrm{O}$ movimento que as mãos descrevem no espaço ou sobre o corpo pode ser em linhas retas, curvas, sinuosas ou circulares em várias direções e posições. (BRITO, 2010 [1995], p. 38).

O Movimento possui características relacionadas ao tipo, à direcionalidade, à maneira e à frequência do movimento. Pode ocorrer movimento das mãos, dos pulsos e dos antebraços. A direção do movimento pode ser unidirecional, bidirecional ou multidirecional. A maneira está relacionada à categoria que descreve a qualidade, a tensão e a velocidade do movimento; e a frequência refere-se ao número de repetições de um movimento.

A Orientação (Or) "é a direção da palma da mão durante o sinal: voltada para cima, para baixo, para o corpo, para frente, para a esquerda ou para a direita. Pode haver mudança na orientação durante a execução do movimento" (BRITO, 2010 [1995], p. 41,). Orientação em alguns sinais pode ter uma direção diferenciada proposital, como, por exemplo, a ideia de oposição, concordância número-pessoal e marcação de tempo.

Expressões Não Manuais (ENM) ou Marca Não Manuais (MNMs) estão presentes em diversos sinais. Assim, "muitos sinais que têm como elemento diferenciador também a expressão facial e/ou corporal, traduzindo sentimentos e dando mais sentido ao enunciado e em muitos casos determina o significado do sinal" (SILVA, 2002, p. 55).

Estudos linguísticos têm ampliado conceitos a respeito dos parâmetros apresentados, dentre eles, a noção de ponto central para articulação. Consoante Nunes (2018), encontramos, no Ponto de Articulação para a produção dos sinais, um ponto central para articulação que não é escolhido aleatoriamente. Devido à corporificação, de forma metafórica e/ou metonímica partes do corpo são selecionadas para a produção de sinais que caracterizam determinados significados. Para exemplificar, em sinais da Libras para ações como comer, falar, gritar e beijar a sinalização é feita próximo à boca e em ações como pensar, lembrar, aprender e esquecer, próximo à testa. Esse tema será retomado nos sinais estudados neste artigo na etapa da análise de dados.

Pressupostos da Linguística Cognitiva no estudo de línguas de sinais

A respeito do recorte teórico para esta seção, descrevemos pressupostos da Linguística Cognitiva e como esses podem ser aplicados para o estudo de línguas de sinais. Dado a extensão do gênero textual artigo, não apresentamos parâmetros fonológicos prototípicos de cada uma das sete línguas de sinais, mas sim fenômenos linguístico-cognitivos recorrentes nessas línguas.

Pensando na dicotomia 'icônico-arbitrário' no estudo de línguas, apresentada por Ferdinand de Saussure (1857-1913), filósofo e linguista suíço, Brito 2010 [1995] esclarece que a iconicidade é mais evidente nas estruturas das línguas de sinais do que nas orais, devido ao fato de o espaço parecer ser mais concreto e palpável. Como as línguas de sinais são produzidas de forma visual, e o corpo está sempre presente no ato da comunicação, a relação dessas línguas com o corpo é inevitável.

Analisando a iconicidade na Língua de Sinais Americana, Wilcox (2004) propõe o estudo da Iconicidade Cognitiva apoiada em pressupostos teóricos da Linguística Cognitiva, em especial na composição de uma estrutura simbólica presente na Gramática Cognitiva de Langacker (1987).

Em relação à Libras, no trabalho de Nunes (2014), encontramos análise linguístico-cognitiva sobre sinais que apontam para sinais icônicos, produzidos por relações corporificadas e metonímicas. Em Nunes (2018), acrescentam-se relações metafóricas e esquemas imagéticos para a 
compreensão dos sinais. Para Nunes (2018), portanto, é possível identificar metáforas, metonímias, esquemas imagéticos e corporificação na produção de sinais. Esses fenômenos linguísticos são colaboradores para a compreensão da iconicidade cognitiva presente em sinais que compõem o léxico de línguas de sinais.

Para compreender como esses fenômenos linguísticos estão atrelados aos sinais, apresentamos a seguir breve conceituação sobre como, na perspectiva da Linguística Cognitiva, são estudados os seguintes tópicos: corporificação, esquemas imagéticos, metonímias, metáforas e iconicidade cognitiva.

Mark Johnson (1987) destaca que a 'corporificação' é encontrada na cognição humana, pois o que falamos ou pensamos está relacionado à experiência corporal sobre como percebemos e concebemos o mundo ao nosso redor. Assim, sentidos, habilidades motoras e perceptuais estão ligados à linguagem e à forma como se conceptualizam conceitos na mente.

A respeito disso, Lakoff e Johnson (1980) descrevem que a mente seria "corporificada", estruturada através das experiências corporais, e não uma entidade puramente metafísica e independente do corpo. Da mesma forma, a razão é também "corporificada", pois se origina tanto da natureza do cérebro como das peculiaridades dos corpos e das experiências no mundo em que se vive.

Partindo da proposta de Lakoff e Johnson (1980), Nunes (2014) propõe, em relação aos estudos de Libras, que a corporificação está atrelada às relações com os órgãos do corpo e suas funções estão presentes na produção de sinais, visto que o corpo é parte integrante na composição dos sinais. Para exemplificar, o sinal NASCER em Libras possui uma motivação corporificada, ou seja, o sinal é realizado na região próxima à barriga e com um movimento indicando a ação de sair da barriga para fora.

Em relação aos esquemas imagéticos, de acordo com Geeraerts (2006), George Lakoff, em colaboração com o filósofo Mark Johnson, propôs o termo 'esquema imagético' no livro 'The Body in the Mind', em 1987. Esse termo se refere aos "esquemas mentais que codificam padrões espaciais e relações de força que identificamos em nossa interação com o ambiente ao redor" (ALMEIDA et al., 2009, p. 21).

Cuenca e Hilferty (2007, p. 107) destacam que "é necessário enfatizar que todos esses esquemas têm como eixo central a imensa importância da experiência corporal". Para Evans e Green (2006), os esquemas imagéticos são caracterizados como concepções relacionadas à experiência do corpo humano que podem sistematicamente providenciar a compreensão de conceitos abstratos e domínios conceptuais. Kövecses (2006) apresenta os seguintes esquemas imagéticos: CONTÊINER, EQUILÍBRIO, CAMINHO, ESCALA, PARTE-TODO, CHEIO-VAZIO, PROCESSO, OBJETO, COLEÇÃO e INTERAÇÃO. Para exemplificar, na Libras, o sinal ALTO apresenta movimento para cima fazendo alusão ao esquema imagético ESCALA, que também é encontrado no sinal BAIXO cujo movimento é para baixo.

A respeito da metonímia, a primeira abordagem sobre a 'Teoria da Metonímia Conceptual' foi desenvolvida por Lakoff e Johnson (1980). Os autores argumentaram que a metonímia é um fenômeno conceptual em que "X substitui Y". Essa substituição é possível porque existe uma estreita relação entre duas entidades pertencentes ao mesmo domínio.

Assim, a metonímia porta uma função principalmente referencial porque é possível utilizar uma entidade em lugar de outra. Não é apenas um dispositivo referencial, mas também apresenta a função de proporcionar o entendimento. Para exemplificar, observa-se, na Libras, o sinal CASA, em que há uma representação manual do telhado de uma casa. Assim, o telhado é um gatilho mental para a representação de casa em que encontramos a metonímia TELHADO POR CASA.

Acerca de das questões metafóricas, a 'Teoria da Metáfora Conceptual' foi introduzida por George Lakoff e Mark Johnson, na obra 'Metaphors we live', em 1980. Para os autores, a metáfora faz parte do sistema conceptual humano, próprio do pensamento, 
capaz de realizar comparações entre dois domínios, permitindo ao emissor e receptor "conceber e exprimir ideias abstratas (...) a partir de sua experiência com entidades ou situações ontologicamente mais básicas" (ALMEIDA et. al., 2009, p. 35).

Kövecses (2006) descreve que a metáfora é um fenômeno linguístico, conceptual, sociocultural, neural e corporificado ao mesmo tempo, envolvendo dois domínios de experiência que estão conectados sistematicamente. Esses dois domínios provêm de diferentes partes do sistema conceptual (do cérebro), cuja conexão é possível porque mostram alguma similaridade genética estrutural, ou porque são correlacionados por nossa experiência, relacionada à mente humana corporificada.

Conceitos abstratos são comumente metafóricos, pois noções abstratas são compreendidas a partir de conceitos concretos. Esse caminho entre dois domínios é a metáfora conceptual, sendo concebida pelo esquema A É B, ou seja, um domínio fonte/origem é projetado em um domínio alvo. Para exemplificar, na Libras, muitas vezes, sinais que expressam sentimentos ruins são sinalizados com movimento para baixo, apresentando a metáfora conceptual RUIM É PARA BAIXO, tais como os seguintes sinais: DEPRESSÃO e TRISTE.

A respeito da Iconicidade Cognitiva, o léxico e a gramática são totalmente descritíveis como conjunto de estruturas simbólicas, ou seja, polo semântico e polo fonológico. Do ponto de vista da gramática cognitiva, a gramática não é distinta da semântica. Segundo Langacker (2008), uma estrutura simbólica $(\Sigma)$ pode ser bipolar, pois ela possui um polo semântico (S) e um polo fonológigo (P). Logo, a estrutura simbólica BOLA pode ser representada da seguinte forma: [[BOLA]/[bola]] - letras maiúsculas para o polo semântico e letras minúsculas para o polo fonológico.

É comum nas línguas que os polos semântico e fonológico de uma estrutura simbólica estejam em regiões distantes do espaço conceitual. A palavra falada para o som de bola, por exemplo, tem pouco em comum com o significado de bola. Essa grande distância no espaço conceitual, resultante da distância entre os polos semântico e fonológico, é a base da arbitrariedade do signo. Entretanto, quando os polos fonológico e semântico de sinais residem na mesma região do espaço conceitual, a arbitrariedade é reduzida. Por isso, na Libras, o sinal BOLA é icônico, tendo em vista que o formato das mãos no pólo fonológico representa o formato de uma bola, trazendo, assim, o conceito desse objeto - pólo semântico.

Um dos motivos da contribuição da representação icônica nas línguas de sinais é que a parte fonológica dos sinais envolve as mãos, o movimento no espaço e a interação com outros objetos. Dessa forma, as concepções de objetos e eventos podem ser iconicamente representadas.

\section{Análise dos dados}

Para a análise dos sinais, investigamos fenômenos linguístico-cognitivos recorrentes nessas línguas a fim de pesquisar como a presença de relações corporificadas, metáforas, metonímias e esquemas imagéticos colaboram para a compreensão da iconicidade cognitiva.

\section{I - APRENDER}

A definição de aprender não foi disponibilizada no Spread the Sign Web Dictionary - SWD. Entendese essa ação de adquirir conhecimento sobre algo.

Figura 1 - Sinal APRENDER na LSF

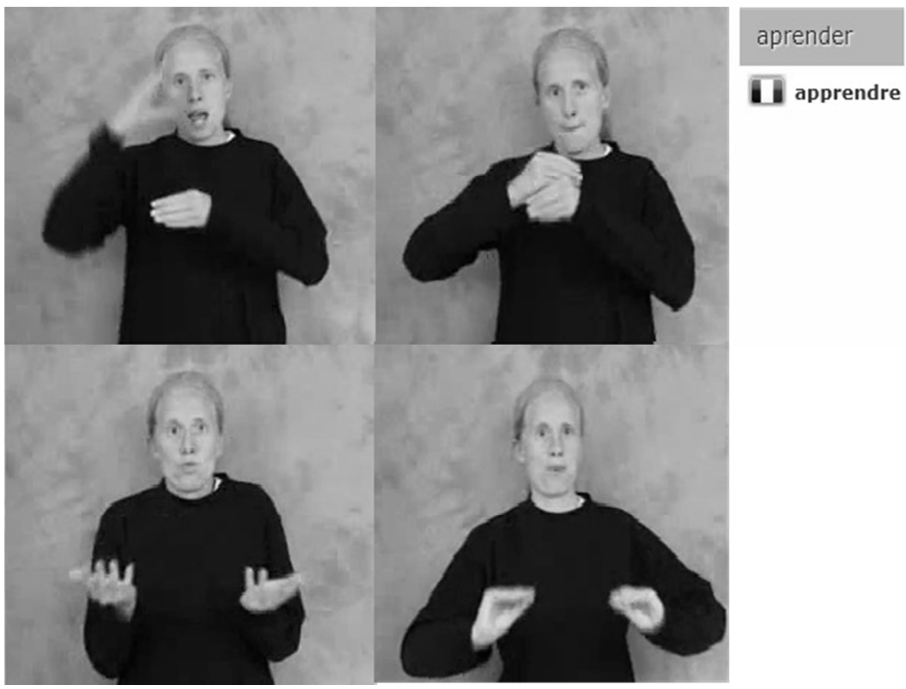

Fonte: www.spreadthesign.com 
Figura 2 - Sinal APRENDER na ASL

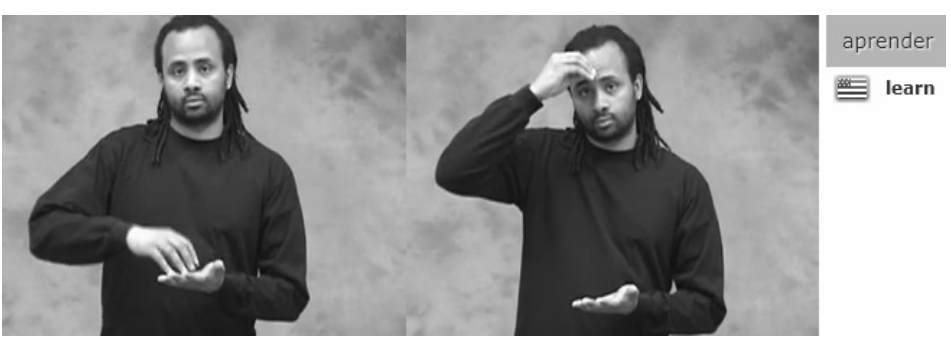

Fonte: www.spreadthesign.com

Figura 3 - Sinal APRENDER na Libras
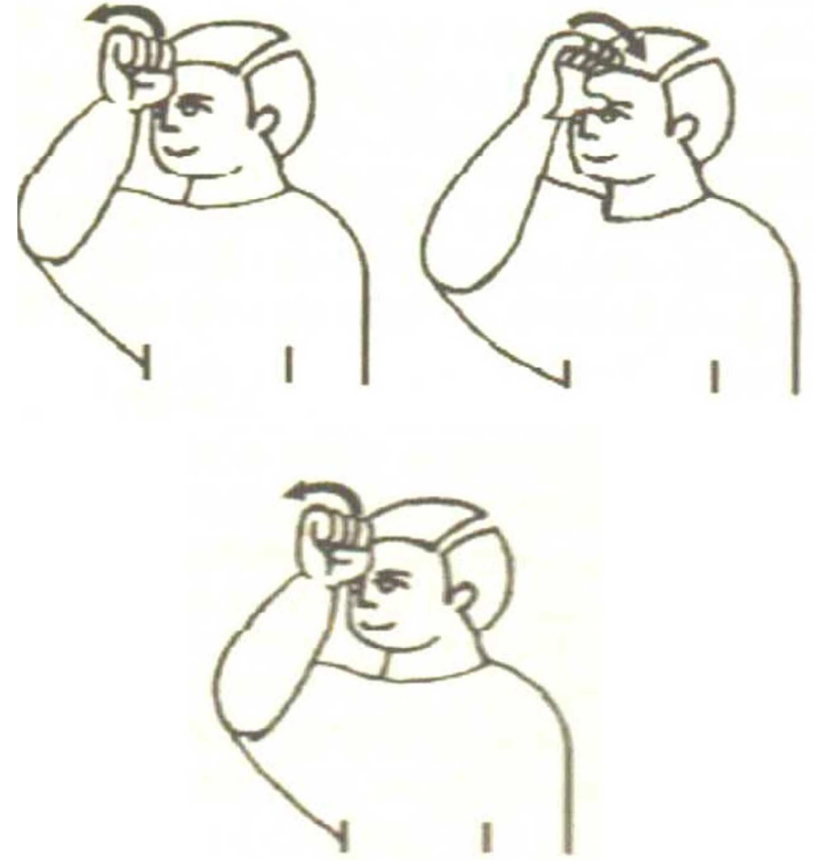

Fonte: CAPOVILLA et al, 2015, p. 395

Figura 4 - Sinal APRENDER na LSS

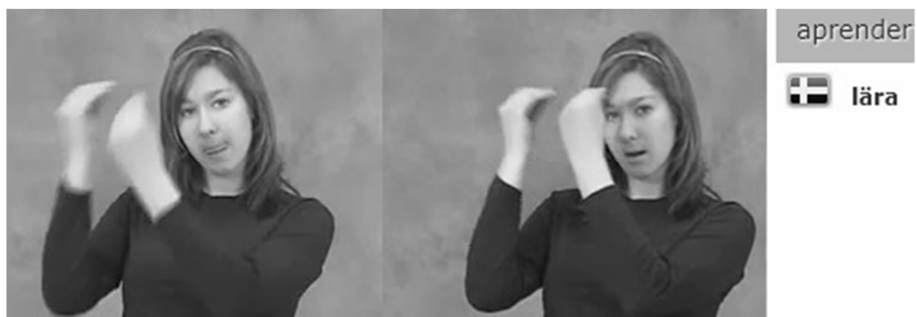

Fonte: www.spreadthesign.com
Figura 5 - Sinal APRENDER na LGP

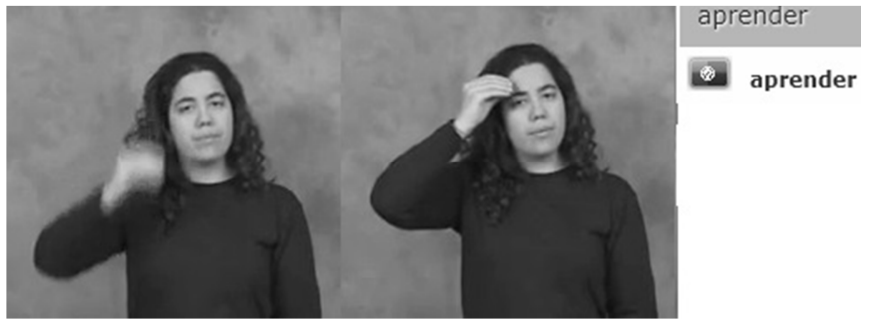

Fonte: www.spreadthesign.com

Figura 6 - Sinal APRENDER na LSJ

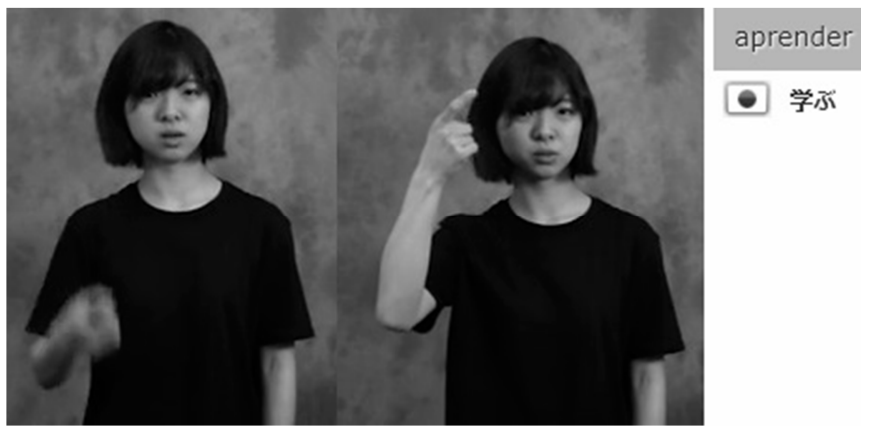

Fonte: www.spreadthesign.com

Figura 7 - Sinal APRENDER na LSC

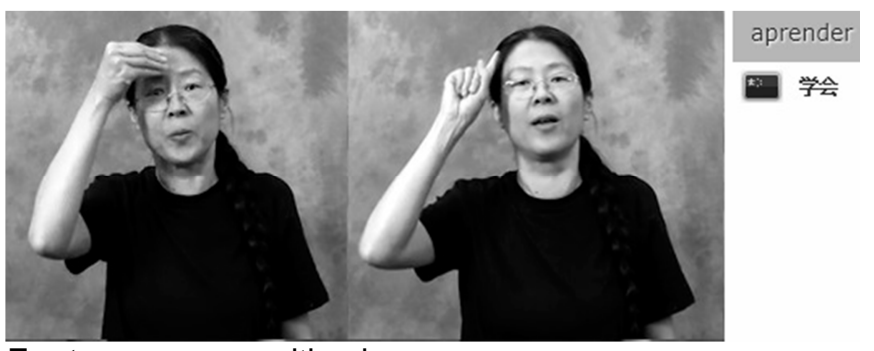

Fonte: www.spreadthesign.com

O ponto central para articulação do sinal em todas as línguas analisadas é a cabeça, parte do corpo em que se localiza o cérebro, órgão responsável pela cognição. Logo, há uma relação corporificada acompanhada da metonímia CABEÇA POR COGNIÇÃO.

O corpo é associado ao esquema imagético CONTÊINER, DENTRO-FORA, sendo o conhecimento algo que é posto de fora para dentro do corpo. Assim, a ação de aprender está associada em inserir entendimento para o interior da cabeça, MENTE É CONTÂINER.

$\mathrm{Na}$ ASL, uma mão passiva simboliza uma base em que a mão ativa retira o "conhecimento" $e$ deposita na mente. Na Libras, a ação de abrir e fechar a mão em frente à testa remete à metáfora 
PEGAR É OBTER, pois aprender uma nova informação, de forma metafórica, é pegar uma informação para por dentro do contêiner, corpo.

$\mathrm{Na}$ LSF, o movimento do sinal começa da cabeça sendo posto nas mãos, em formato circular, gerando um movimento, posterior, com as duas mãos sendo elevadas. Nesse caso, aprender está atrelado ao esquema imagético ESPAÇO, EM CIMA - EMBAIXO, sendo o aprendizado uma forma de elevação.

II - ESQUECER

No Spread the Sign Web Dictionary - SWD, esquecer é a ação de perder a lembrança, deixar de lembrar, retirar da memória.

Figura 8 - Sinal ESQUECER na LSF

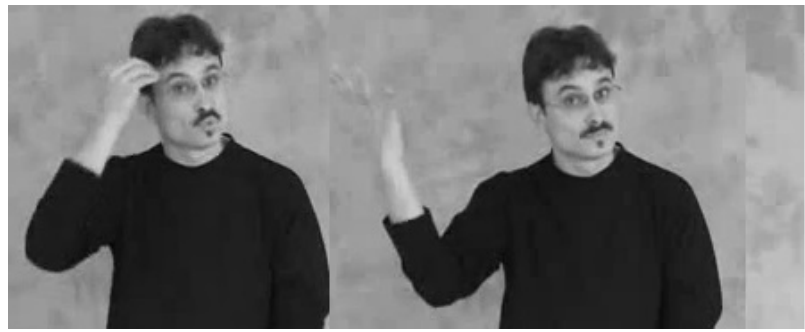
esquecer II oublier

Fonte: www.spreadthesign.com

Figura 9 - Sinal ESQUECER na ASL

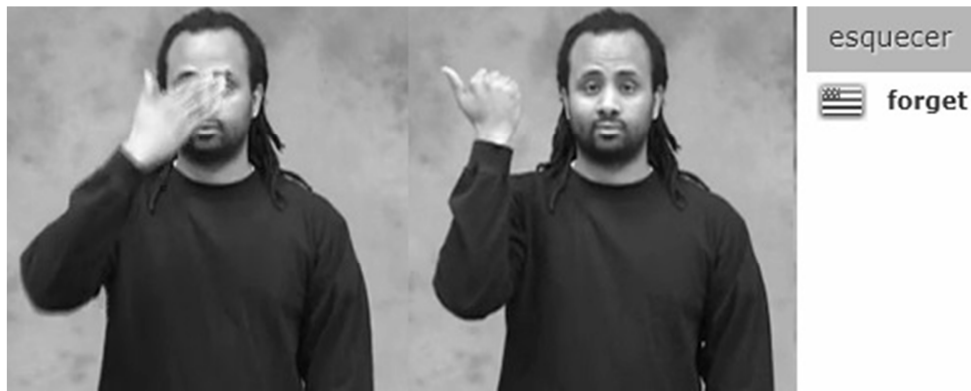

Fonte: www.spreadthesign.com

Figura 10 - Sinal ESQUECER na Libras

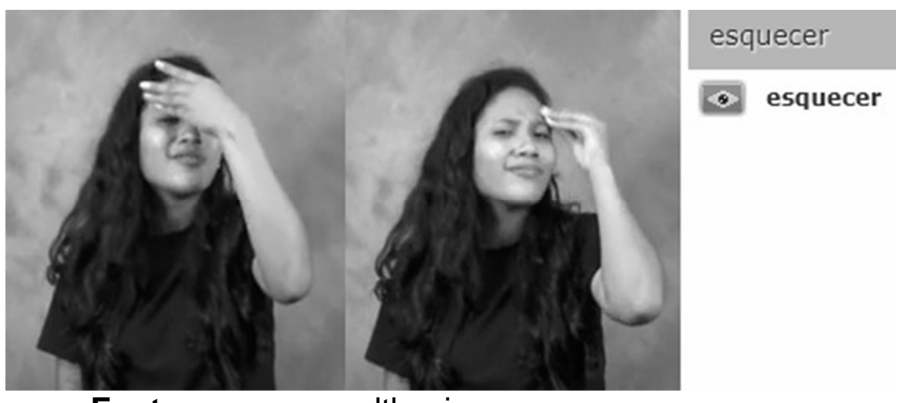

Fonte: www.spreadthesign.com
Figura 11 - Sinal ESQUECER na LSS

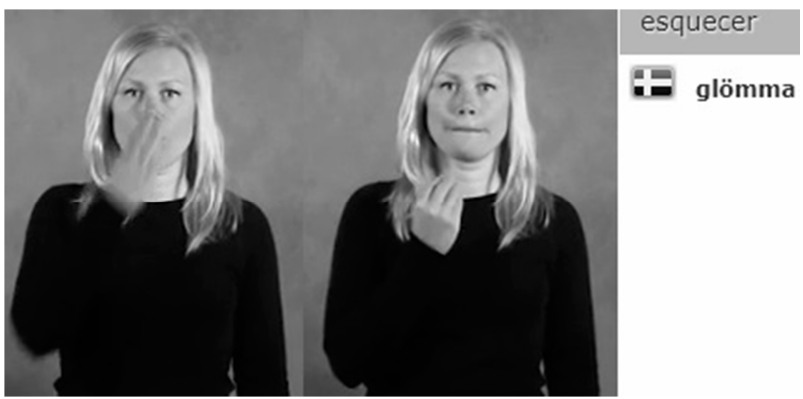

Fonte: www.spreadthesign.com

Figura 12 - Sinal ESQUECER na LGP

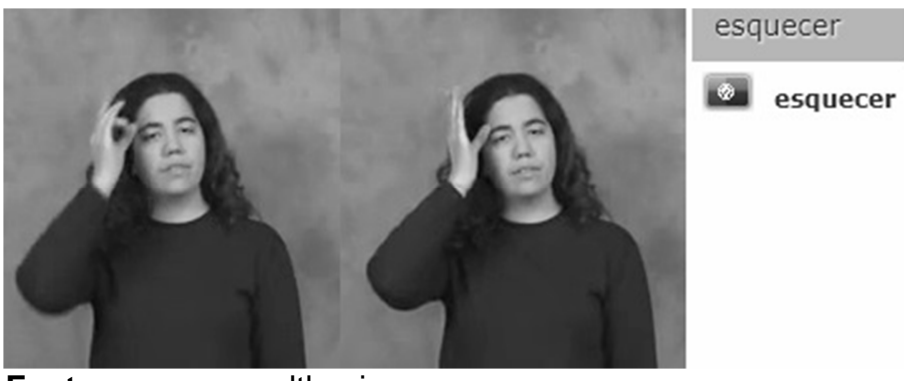

Fonte: www.spreadthesign.com

Figura 13 - Sinal ESQUECER na LSJ

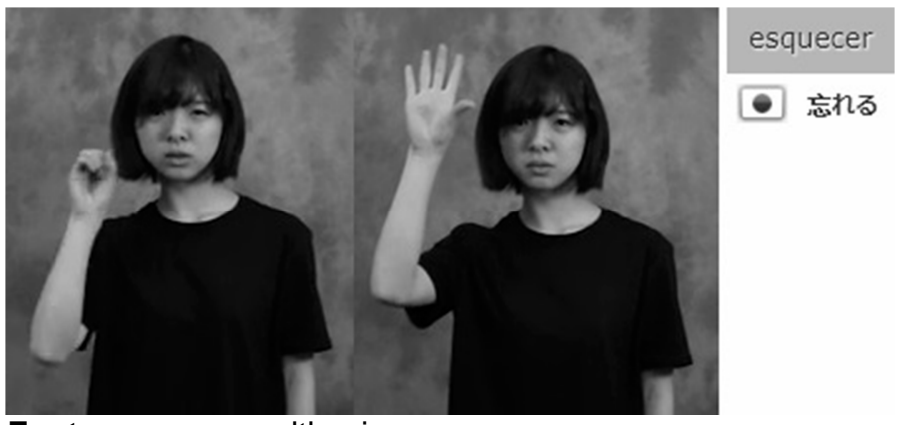

Fonte: www.spreadthesign.com

Figura 14 - Sinal ESQUECER na LSC

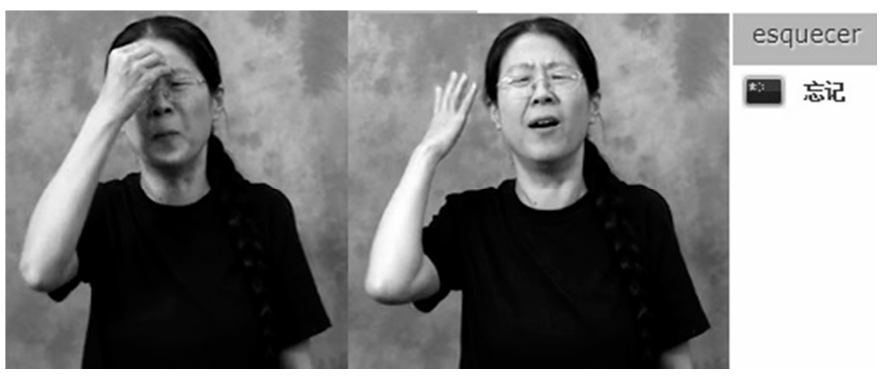

Fonte: www.spreadthesign.com

Observa-se em todos os sinais o esquecimento sendo retratado como algo para fora da mente, que saiu da cabeça. Assim, a metonímia corporificada CÉREBRO POR COGNIÇÃO é percebida acompanhada do esquema imagético CONTÊINER, DENTRO-FORA. Esquecer é a retirada de uma informação da mente. 
A metáfora PEGAR É OBTER está presente, pois existe uma representação de pegar com as mãos uma informação da mente. $\mathrm{Na}$ LSF, inicia-se a sinalização com a ilustração de algo que estava guardado e depois é solto, seguido da mão como uma garra, que pega algo da mente, e depois solta. $\mathrm{Na}$ Libras, LSS, ASL, LSF, há esse movimento de pegar da mente uma informação. Na LSC e na LSJ, de forma metafórica, a informação presa é solta em um espaço neutro.

\section{Considerações finais}

A ação de se comunicar faz parte das relações sociais dos homens e, para estabelecer essa comunicação, por meio de uma língua visual, o ser humano pode partir de seu corpo para produzir essa língua. Nas sete línguas de sinais estudadas, verificou-se que a relação com o corpo manteve-se presente, por processos cognitivos atrelados à iconicidade cognitiva, motivada por esquemas imagéticos, corporificação, metáforas e metonímias.

Propôs-se, neste estudo, apontar alguns caminhos para investigar processos cognitivos na produção de sinais. Optou-se pelo arcabouço teórico da Linguística Cognitiva porque ela possibilita a compreensão dos fenômenos linguísticos por meio da interação entre recursos corporais e cognitivos através de uma análise de percepções visuais.

A respeito dos estudos fonológicos para descrição das línguas de sinais, com base nos pressupostos da Línguística Cognitiva, apresentaramse algumas contribuições sobre o Ponto de Articulação.

O Ponto de Articulação, tradicionalmente, tem sido compreendido como o parâmetro fonológico que indica o local em que se realiza o sinal. Entretanto, esses pontos não são escolhidos aleatoriamente. Por isso, defendeu-se o conceito de ponto central entendido como locais específicos de significação para a produção do sinal.

Esses pontos centrais de articulação são carregados de significados produzidos a partir experiências corporais humanas com o ambiente. Por isso, conceitos relacionados ao raciocínio humano, geralmente, têm como ponto central a cabeça (APRENDER/ESQUECER nas línguas de sinais estudadas).

Devido à pequena extensão desta pesquisa, não se objetivou apresentar caminhos que possam generalizar a análise de sinais, mas apontar possibilidades de investigação. Assim, por meio da apresentação de reflexões sobre como teorias e pressupostos da Linguística Cognitiva (LC) podem ser aplicados em línguas de sinais e por meio da descrição de algumas estratégias cognitivas utilizadas na produção de sinais, espera-se que este estudo seja uma fonte de pesquisa para estudiosos da LC e de língua de sinais.

\section{Referências}

ALMEIDA, Maria Lúcia Leitão et al. (Org.). Linguística cognitiva em foco: morfologia e semântica do português. Rio de Janeiro: Publit, 2009.

BRITO, Lucinda Ferreira. Por uma gramática de língua de sinais, reimpr. Rio de Janeiro: Tempo Brasileiro, 2010 [1995].

CAPOVILLA, Fernando César, RAPHAEL, Walkiria Duarte, MAURICIO, Aline Cristina L. Novo DeitLibras: dicionário enciclopédico ilustrado trilíngue da língua de sinais brasileira. 3. ed. São Paulo: Editora EDUSP, 2015.

CUENCA, Maria Josep; HILFERTY, Joseph. Introducción a la linguística cognitiva. Barcelona: Editora Ariel, S.A, 2007.

EVANS, Vyvyan; GREEN, Melanie. Cognitive linguistics: an introduction. Edinburgh: Edinburgh University Press, 2006.

GEERAERTS, Dirk (Ed.). Cognitive linguistics: basic readings. Berlin/New York: Mouton de Gruyter, 2006.

KÖVECSES, Zóltan. Language, mind and culture: a practical introduction. New York: Oxford University Press, 2006.

Cognitive grammar: a basic introduction. New York: Oxford University Press, 2008.

LAKOFF, George; JOHNSON, Mark. Metaphors we live by. Chicago: University of Chicago Press, 1980. 
LANGACKER, Ronald W. Foundations of cognitive grammar, v.1. Stanford: Stanford University Press, 1987.

NUNES, Valeria Fernandes. Narrativas em Libras: análise de processos cognitivos. Dissertação (Mestrado em Linguística) Universidade do Estado do Rio de Janeiro, Rio de Janeiro, 2014.

Corporificação e iconicidade cognitiva: um estudo sobre verbos em línguas de sinais. Tese (Doutorado em Linguística) - Instituto de Letras, Universidade do Estado do Rio de Janeiro, Rio de Janeiro, 2018.

SILVA, Fábio I.; SCHMITT, Deonísio; BASSO, Idavania M. S. Língua brasileira de sinais: pedagogia para surdos. Florianópolis: UDESC/CEAD, 2002.

WILCOX, Sherman. Cognitive iconicity: conceptual spaces, meaning, and gesture in signed languages. Germany: Walter de Gruyter, 2004.

\section{COMO CITAR ESSE ARTIGO}

NUNES, Valeria Fernandes. Contribuições da Linguística Cognitiva para o estudo de línguas de sinais. Signo, Santa Cruz do Sul, v. 44, n. 81, jan. 2020. ISSN 1982-2014. Disponível em: $<$ https://online.unisc.br/seer/index.php/signo/article/view/13717>. Acesso em: doi: https://doi.org/10.17058/signo.v44i81.13717. 